\title{
Princípio da integralidade numa UTI pública: espaço e relações entre profissionais de saúde e usuários ${ }^{1}$
}

\section{Principle of integrality in a public UTI : space and relations between health professionals and users}

\section{Principio de integralidad en una UTI : espacio e relaciones entre profesionales de salud y usuarios}

Rosangela de Oliveira', Sônia Ayako Tao Maruyama"

\begin{abstract}
${ }^{1}$ Este artigo é parte da dissertação de Mestrado "A Integralidade nas Práticas de Controle de Infecção na UTI de um serviço público de saúde" apresentada ao Programa de Pós-Graduação da Faculdade de Enfermagem da Universidade Federal de Mato Grosso (FAEN/UFMT) e sub-projeto do Projeto de Pesquisa "O atendimento aos princípios da integralidade e da resolutividade na atenção à saúde no contexto do SUS na área de abrangência da BR 163 no Estado de Mato Grosso" financiado pelo CNPq sob o no 402866/2005-3 - Ed. 342005-BR163 2aEt/Edital MC/CNPq/MS-SCTIE-DECIT 34/2005-Área de Influência BR 163.

' Enfermeira. Mestranda em Enfermagem pela UFMT, Especialista em Administração de Serviços de Saúde e em Infecção Hospitalar. Fiscal Sanitário da Vigilância Sanitária de Cuiabá-MT. Email: rowioliveira@gmail.com.

"Enfermeira. Doutora em Enfermagem Fundamental pela EERP/USP. Professor Adjunto FAEN/UFMT. Email: soniayako@uol.com.br.
\end{abstract}

\section{RESUMO}

O princípio da integralidade no Sistema Único de Saúde representa um atributo desejável em todos os níveis de atenção em saúde. Nessa perspectiva, o objetivo do estudo é compreender como esse princípio é observado na assistência aos usuários de uma Unidade de Terapia Intensiva (UTI) pública. Trata-se de uma pesquisa qualitativa de abordagem compreensiva, embasada nos referenciais da integralidade e em alguns conceitos de Michel Foucault, realizada numa UTI pública em 2007 por meio da técnica da observação participante. Para a análise dos dados, foi utilizada a análise de conteúdo proposta por Minayo. De acordo com o objetivo proposto, identificamos que o espaço da UTI e as relações entre profissionais de saúde e pessoas doentes são aspectos que desafiam o respeito a este princípio na terapia intensiva estudada. Concluímos que, para o atendimento à integralidade aos usuários da UTI, torna-se necessária a reorganização das práticas de saúde mediante o resgate do compromisso com esses usuários, de forma a considerar na assistência em saúde os aspectos bio-psico-sociais, valorizando também outras dimensões que se encontram abaladas além da dimensão biológica.

Descritores: Atenção à Saúde; Unidade de Terapia Intensiva; , Cuidados de Enfermagem.

\section{ABSTRACT}

El principio de integralidad en el Sistema Único de Salud representa un atributo deseable en todos los niveles de atención en salud. En esa perspectiva, el objetivo del estudio es comprehender como ese principio es observado en la asistencia a los usuarios de una UTI pública. Se trata de una pesquisa cualitativa de abordaje comprehensiva, basada en los referenciales de integridad y en algunos conceptos de Michel Foucault, realizada en una UTI pública en 2007, por medio de la técnica de observación participante. Para el análisis de los datos, utilizamos el análisis del contenido propuesto por Minayo. De acuerdo con este objetivo, identificamos que en las relaciones entre los profesionales de salud y los enfermos de la UTI hay aspectos que desafían el respeto a este principio en la terapia intensiva estudiada. Concluimos que, para atender el principio de integralidad a los usuarios de la UTI, se torna necesaria la reorganización de las prácticas de salud, por medio del rescate del compromiso con eses usuarios, de modo a considerar los aspectos bio-psico-sociales, valorando también otras dimensiones que se encuentran estremecidas allá de la dimensión biológica.

Descriptors: Health Care; Intensive Care Units; Nursing Care.

\section{RESUMEN}

The principle of integrality in the Single Health System represents a desirable attribute in all levels of attention in health. In this perspective, the objective of this study is to understand how this principle is perceived in the assistance to users of a public Intensive Care Unit (ICU). It's a qualitative research of comprehensive approach, based in integrality references and some concepts of Michel Foucault. This study was conducted in a public ICU in 2007, through the technique of participant observation. For the data analysis, was used the content study proposed by Minayo. According to the proposed objective, we identified that the ICU's area and the relationships between health professionals and patients are aspects which challenge the respect to this principle in the intensive therapy studied. We conclude that for attendance to integrality the ICU's users, becomes necessary the reorganization of health practices in order to rescue the compromise with this users, so to consider in the health assistance the aspects biopsycho-social, in order to valorize other dimensions, which are damaged besides biological dimension.

Descriptores: Atención a la Salud; Unidad de Terapia Intensiva; Atención de Enfermería. 


\section{NTRODUÇÃO}

O Sistema Único de Saúde (SUS) se organiza de acordo com três diretrizes básicas: a descentralização das ações, o atendimento integral e a participação social ${ }^{(1)}$. Atendimento integral ou princípio da integralidade, foco desse estudo, são termos que apresentam o mesmo significado e vêm sendo utilizados com uma freqüência cada vez mais habitual no contexto da assistência à saúde. Relacionam-se ao ideal de uma sociedade mais justa e solidária(2). A integralidade é entendida e explicada como

“um princípio fundamental do SUS. Garante ao usuário uma atenção que abrange as ações de promoção, prevenção, tratamento e reabilitação, com garantia de acesso a todos os níveis de complexidade do Sistema de Saúde. A integralidade também pressupõe a atenção focada no indivíduo, na família e na comunidade (inserção social) e não num recorte de ações ou enfermidades"(3).

Baseado no exposto, a integralidade representa o modo de indicar as características desejáveis do sistema de saúde e de suas práticas assistenciais ${ }^{(4)}$, bem como de superar as características reais ou existentes nos serviços. Expressam, também, o atributo das boas práticas de saúde, de como devem ser organizados os serviços e de suas políticas ${ }^{(5)}$, objetivando permitir uma assistência em saúde que perpasse a dimensão puramente biológica.

A integralidade é percebida como um compromisso profissional que considera os aspectos que se relacionam e influenciam as dimensões da pessoa doente, ou seja, de um agir ético, tendo como proposição a emancipação dos sujeitos profissionais e usuários em busca da qualificação de suas vidas.

Portanto, a integralidade se torna um atributo desejável em todos os níveis de atenção, e, para tanto, envolve a necessidade de mudanças de atitude ética e técnica dos profissionais de saúde ${ }^{(6)}$.

Os usuários que necessitam de assistência hospitalar se encontram num estado de maior fragilidade, seja biológica, psíquica ou social, uma vez que a internação faz com que sejam experienciados sentimentos diversos, causados pela alteração do cotidiano das pessoas e das famílias.

$\mathrm{Na}$ internação em uma Unidade de Terapia Intensiva (UTI) a fragilidade e a vulnerabilidade são potencializadas, em função da concepção que as pessoas têm sobre essas unidades, expressas por muitos como um espaço da própria terminalidade, não sendo vistas como local que se destina ao tratamento e recuperação dos enfermos ${ }^{(7)}$.

Para a monitorização e vigilância constante dos pacientes, a UTI agrega em sua estrutura, recursos humanos qualificados e recursos tecnológicos capazes de garantir a manutenção, suporte à vida e possibilidade de recuperação de pacientes que se encontram em condição de gravidade.
Os pacientes de UTI recebem, portanto, a assistência necessária à manutenção de suas vidas por equipes multiprofissionais especializadas e instrumentalizadas com tecnologias de alta complexidade, capazes de intervir diante das diferentes situações de alteração de seus padrões vitais.

Entretanto, se por um lado as pessoas internadas numa UTI vivenciam toda uma aproximação de pessoas dotadas de conhecimentos especializados, amparadas por recursos tecnológicos avançados, por outro lado, vivenciam períodos de afastamento do seu cotidiano, como a família, os amigos, os hábitos e as crenças. Angustiam-se com a sua condição de enfermidade, com a dor, com sua privacidade invadida por pessoas que não conhece, com o medo do desconhecido e com a perda da sua identidade.

Numa UTI, a especificidade da assistência difere de outras unidades do hospital, pois "possui rotinas diferenciadas [...] sendo apontadas por alguns autores como rígidas e inflexíveis, que afastam o paciente do convívio com seus familiares e do seu ambiente" ${ }^{\prime(8)}$, tornando a internação uma experiência difícil e dolorosa para as pessoas doentes e para os familiares que, também partilham desse momento. Isso gera estresse, preocupação e sofrimento e traz consigo, sentimentos de insegurança, perda da independência e da identidade, baixa na auto-estima, afastamento do convívio social e outros ${ }^{(9)}$.

Diante do processo vivenciado pela experiência da internação numa UTI, tanto para pacientes como também para seus familiares, verificamos a importância do atendimento aos princípios da integralidade pelos profissionais e serviços de saúde como forma de amenizar o sofrimento causado às pessoas durante a permanência no hospital.

Assim, esse estudo teve como objetivo compreender como o princípio da integralidade é percebido na assistência aos usuários de uma UTI pública. Nessa perspectiva, esperamos com este estudo desencadear a reflexão acerca da assistência prestada aos usuários dos serviços de saúde no atendimento a esse princípio do sistema público de saúde brasileiro.

\section{PERCURSO METODOLÓGI CO}

Estudo qualitativo embasado na abordagem compreensiva. Para tanto, a pesquisa qualitativa nos permitiu compreender o contexto onde um determinado fenômeno ocorre, objetivando um entendimento mais profundo e até subjetivo do objeto de estudo ${ }^{(10)}$, enfocando as particularidades e as especificidades dos grupos sociais estudados. A abordagem compreensiva nos possibilitou a compreensão e a interpretação dos fenômenos que ocorrem nos processos da assistência em saúde. 
O estudo foi realizado na UTI Adulto de um hospital público do município de Cuiabá/MT, após a aprovação pelo Comitê de Ética em Pesquisa envolvendo Seres Humanos através do ofício CEP/ HUJ M no 296/2006, e após a assinatura dos Termos de Consentimento Livre e Esclarecido pelos profissionais da UTI. Os sujeitos da pesquisa foram compostos pelos profissionais que atuam na UTI, num determinado período do dia. A fase de campo ocorreu no período de fevereiro a maio de 2007. As observações participantes foram realizadas num período de 3 horas em média, em dias alternados, sendo utilizados nesta fase dois instrumentos: o registro de observações e o diário de campo.

Para a coleta dos dados, optamos pela técnica da observação participante das práticas profissionais na UTI, uma vez que possuem considerável importância no trabalho de campo das pesquisas qualitativas como estratégia de investigação ou como método para compreender a realidade. Tende a ser a mais profunda possível, seja através do método observacional ou do cotidiano em que se inserem pesquisador e os profissionais observados, onde as rotinas se realizam e os fatos acontecem ${ }^{(11)}$.

Essa técnica nos possibilitou a apreensão de muitos elementos que, normalmente, não podem ser captados pelo pesquisador, como a fala ou a escrita. Há de se considerar também o ambiente, os comportamentos, as linguagens não-verbais, as seqüências e temporalidades nas quais os eventos ocorrem, na perspectiva de que essas informações subsidiem a interpretação dos eventos ${ }^{(12)}$.

A saída do campo se deu a partir do momento em que começamos a observar a saturação dos dados, ou seja, quando observamos que eles se tornavam repetitivos.

A análise dos dados foi realizada de acordo com a análise de conteúdo proposta por Minayo ${ }^{(11)}$, onde identificamos como categorias "o espaço na UTI", "as relações entre profissionais de saúde e usuários" e "as relações entre profissionais de saúde e familiares desses usuários".

Neste estudo, nos limitaremos a apresentar apenas duas dessas categorias.

\section{APRESENTAÇÃO DOS RESULTADOS}

\section{O espaço na UTI}

$\mathrm{Na}$ conformação do espaço hospitalar, as terapias intensivas surgiram para aperfeiçoar a assistência a pessoas gravemente enfermas e em risco de morte. Neste espaço, as características da assistência são: o cuidado contínuo, os recursos humanos especializados e a utilização de altas tecnologias de diagnose e terapia ${ }^{(13)}$.

Os recursos humanos especializados e o aparato tecnológico da UTI se relacionam com a organização das práticas assistenciais, o que demonstra como esse espaço é conformado em torno do conhecimento da prática médica: o saber clínico. Portanto, este espaço valoriza esse saber, que privilegia o tratamento das doenças em detrimento do tratamento das pessoas em condição de gravidade. Reserva-se a tratar a doença instalada em um corpo e não a cuidar de uma pessoa cujo corpo está com a doença, conforme podemos visualizar no diário de campo abaixo.

$\mathrm{Na}$ UTI, em alguns momentos, parece não existir uma pessoa internada, e sim, corpos sendo mantidos por aparelhos e equipamentos de alta tecnologia, comandados por robôs, que os monitorizam no sentido de mantê-los vivos, conformando-a como um espaço de tratamento de corpos e não de seres humanos antes de tudo (Diário de Campo de 27/02/07).

O entendimento de que o hospital está organizado para atender a doença e não o doente ${ }^{(14)}$ nos leva a refletir sobre o real papel de uma UTI: cuidar de corpos com doenças complexas ou cuidar de pessoas que passam por uma condição de gravidade no seu processo saúde-doença.

Quando nos reportamos à historicidade dos hospitais, verificamos que, com a inserção do médico nesse espaço, este se torna um local de exame, de controle, de práticas e de saberes médicos ${ }^{(15)}$, tornando a doença e não o doente como o principal foco da atenção médica. A doença é isolada da pessoa, conformando um campo esquadrinhado, onde a doença é valorizada em detrimento da pessoa doente.

Esse processo é característico do sistema sócioeconômico pelo qual as sociedades foram construídas com bases no capitalismo, onde se busca a valorização do corpo do trabalhador para atender às demandas econômicas. Assim, os serviços de saúde foram reorganizados na perspectiva de tratar as doenças ${ }^{(15)}$, de forma a garantir as forças de trabalho necessárias ao modelo capitalista. Os hospitais tornam-se espaço de cura das doenças, através dos mecanismos chamados por Foucault de disciplinas ${ }^{(15)}$. O médico, então, torna o espaço hospitalar medicalizado e se constitui na sua principal figura hierárquica.

No contexto assistencial do espaço da UTI, privilegia-se a circulação dos profissionais de saúde, portanto de pessoas que possuem o saber clínico, sendo $O$ trânsito dos visitantes restrito e desvalorizado nesse espaço. $O$ acesso e a circulação de um "estranho" na UTI é difícil e depende da avaliação do profissional de saúde, que nem sempre valoriza outras dimensões importantes para o doente, como a presença da família e o cuidado espiritual, por exemplo.

$\mathrm{Na}$ entrada das visitas na UTI, um senhor se apresentou como pastor e disse para a técnica de enfermagem Amanda que gostaria de entrar na UTI 
para fazer orações para as pessoas que estavam ali internadas. A técnica o informou que poderia fazê-lo assim que terminasse o horário de visitas, porém, nos confidenciou que a enfermeira responsável pelo plantão não gosta que entrem na UTI para fazer oração para os pacientes, mas que todos precisam de oração e que caberia aos pacientes e familiares decidirem (Registro de Observação de15/02/07).

O espaço da UTI favorece o trânsito de pessoas que tem conhecimento da ciência médica - os profissionais de saúde - em detrimento das outras pessoas usuárias do serviço, como os pacientes, seus familiares e visitantes. $O$ fato de ser permitido o livre acesso dos profissionais de saúde privilegia o saber clínico. Isso causa a desvalorização das outras dimensões dos familiares que tem seu ente confinado nesse espaço tempo.

A circulação interna (da UTI) é restrita aos profissionais e não há sinalização que indique como transitar no hospital às pessoas estranhas, ou seja, as que não fazem parte do cotidiano da instituição, como os familiares e os visitantes dos pacientes. Estes, portanto, são pessoas consideradas excluídas do processo (Diário de Campo de 15/02/07).

A falta de sinalização interna no hospital não atemoriza os profissionais pela cotidianidade do trânsito no trabalho. Entretanto, se para os profissionais o trânsito no hospital faz parte do seu cotidiano, para os familiares ou visitantes, causa transtornos e impõe dificuldade para acessar esse espaço restrito que Ihes é estranho e adverso ao seu cotidiano e se apresenta repleto de mistério ${ }^{(8)}$.

Há alguns anos atrás, as visitas eram ainda mais restritas. Algumas UTIs não permitiam sequer a entrada das pessoas no seu espaço. O contato dos familiares e visitantes com as pessoas internadas se dava através de visores ou janelas que impediam o contato físico. Essa restrição distinguia mais ainda as pessoas que dispunham desses saberes, caracterizando o espaço como um campo de saber e de domínio médico-hegemônico. Entretanto, mudanças vêm ocorrendo ao longo dos tempos, no sentido de desconstruir essa concepção de isolamento do paciente crítico.

Quando nos referimos a relações de saberpoder, observamos que elas permeiam o cotidiano da UTI.

Orientávamos Dona Antonia quanto aos seus direitos como usuária do SUS quando fomos interrompidas pela médica plantonista que, do posto de enfermagem, informou à Dona Antonia que o horário de visitas havia acabado (Registro de Observação de 15/03/07).

As análises foucaultianas apontam para o poder, não como uma coisa, um objeto, mas como uma prática social e historicamente constituída ${ }^{(16)}$. Encontra-se em qualquer nível da escala social e pode ser visualizada de forma sutil ou expressa, quando nos atentamos para a conformação dos espaços nos serviços de saúde. Nos diferentes processos que envolvem as atividades cotidianas no hospital, as relações de saber-poder estão presentes e permeiam todos os espaços, gerando relações assimétricas entre os diferentes atores envolvidos pela busca de domínios de espaços, competitividade e conflitos.

No registro de observação, a intervenção do profissional médico em relação às orientações que eram disponibilizadas à visitante revela a busca da defesa e a delimitação do seu território na UTI, procurando mantê-lo sob seu controle, o que, de certa forma, o afasta dos usuários. Estes, por sua vez, buscam pelo profissional que Ihes possibilita aproximação, de forma a ter suas necessidades atendidas através da possibilidade do processo dialógico.

Em outra situação, a relação saber-poder instituída no espaço hospitalar pode ser visualizada num discurso que foi observado entre o profissional médico e um familiar no horário de visitas.

Dona Antonia, mãe de um paciente internado com traumatismo craniano e fratura de fêmur, questionou a médica plantonista Natália sobre o fato do seu filho ter sido internado na UTI sem qualquer problema pulmonar, conforme foi-lhe dito na internação e depois de alguns dias, ter desenvolvido pneumonia e febre. A médica respondeu à Dona Antonia que apesar dos ventiladores mecânicos salvarem vidas, eles têm este inconveniente de causarem pneumonia nos paciente e que é comum o desenvolvimento de pneumonia nos pacientes em ventilação mecânica (Registro de Observação de 15/03/07).

Os usuários dos serviços hospitalares nem sempre tem conhecimento acerca das doenças e seus tratamentos. Seu saber sobre a clínica geralmente é limitado, o que os impede de fazer novos questionamentos. Assim, nesse contexto, onde ocorre o diálogo entre o profissional de saúde e o usúario, prevalece o domínio de um sobre o outro, pois o discurso do profissional, geralmente do médico, está sustentado pela ciência médica, conformando como verdade tudo o que diz.

Na existência da íntima relação do saber com o poder, Machado(16) explica ainda que, os saberes constituem-se como um elemento necessário para as relações de poder e que, nesse contexto, tornam-se dispositivo político nas disputas de forças e dominação.

O relato que segue, demonstra o questionamento de um familiar, contestando o que Ihe foi informado.

Dona Antonia, mãe do paciente Túlio, reclamou que, no plantão noturno anterior, foi até a unidade para ver como estava seu filho e que quando chegou, observou que o frasco de drenagem da sonda nasogástrica (SNG) estava cheio e refluindo para o 
estômago de seu filho. Vendo o que ocorria, de imediato, chamou uma funcionária da enfermagem, sem saber referir o nome. A funcionária esvaziou o frasco e disse à Dona Antonia que não haveria nenhum problema em decorrência disso, o que a deixou preocupada, pois ela achava que isso não era normal (Registro de Observação de 15/03/2007).

Quando se trata de quem detém o conhecimento clínico, ou seja, o profissional de saúde, este se utiliza dessa ferramenta para manter a sua posição de superioridade na relação profissional-usuário no espaço da UTI. Essa prática não valoriza as dimensões do outro enquanto pessoa com direitos, inclusive de informações relativas à assistência e ao tratamento realizado.

Observamos que, assim como existem os macropoderes, existem também os micropoderes permeando o espaço hospitalar. A atitude do familiar de não aceitar a forma como o seu ente estava sendo cuidado, através da contestação do que lhe foi informado, possibilita reflexões quanto à falta de valorização da subjetividade das pessoas e do senso comum pelos profissionais de saúde, pois se "ela achava que isso não era normal", como poderia aceitar?

Por outro lado, como alguém que não tem o conhecimento técnico pode questionar se o profissional é que detém o saber necessário para atuar naquele espaço ao qual é seu campo de domínio?

Nesse aspecto, Foucault denominou microfísica do poder, pois para ele, o poder não se exerce apenas no nível central. Ele também se exerce nas extremidades. Ele não visa somente esquadrinhar, adestrar, dominar pelas relações de poder, mas sim, servir como um mecanismo de luta e articulação contra essas mesmas relações de poder ${ }^{(16)}$.

Quando nos referimos à organização do seu espaço, a UTI é permeada por disciplinas em todos os processos que envolvem o seu funcionamento e os seus trabalhadores. O controle do desenvolvimento das atividades no hospital é realizado através de horários pré-estabelecidos ou normalizados. Quando se trata do horário de preparo de medicamentos, a equipe de enfermagem prioriza este procedimento, em detrimento de quaisquer outros cuidados, sendo religiosamente respeitados num processo de disciplinarização do processo de trabalho, com o objetivo de garantir a eficácia ou efetividade das drogas utilizadas.

16 h no relógio da UTI. Com a movimentação, percebemos que a equipe de enfermagem se preparava para o procedimento de preparo dos medicamentos quando observamos que as técnicas de enfermagem começavam a juntar os materiais necessários ao procedimento, recolhendo-os das gavetas da pia/balcão do posto de enfermagem com as mãos enluvadas (Registro de Observação de 22/03/07).

Nesse momento, a medicação torna-se o cuidado principal a ser dispensado aos pacientes. Nada parece ser mais importante que esse cuidado, cuja administração é realizada pontualmente dentro dos horários pré-fixados nas prescrições dos pacientes, que tendem a se encaixar nos horários normalizados pelo hospital. Dentro desse espaço disciplinado, as normalizações representam mecanismos disciplinares, uma vez que têm a finalidade de controlar e de corrigir operações naquele espaço.

As normalizações, embora sejam dispositivos que visem disciplinar procedimentos, dependem de vários elementos para que percebam os resultados a que se propõe. Dentre esses elementos, estão os comportamentos, a formação e as subjetividades de cada profissional.

A disciplina é evidenciada na atuação dos profissionais quando eles se preparam ao mesmo tempo, para executar a administração de medicamentos, segundo a rotina hospitalar. Os doentes são cuidados, porém, suas particularidades, suas especificidades, não têm sido relevadas. Neste sentido, muitas vezes, os profissionais de enfermagem tomam as pessoas doentes como objetos e como instrumentos do seu exercício, ao mesmo tempo(17). Essa disciplina é visualizada no exercício das atividades da equipe de enfermagem que realiza os cuidados assistenciais segundo o seu período laboral na UTI e seguindo uma distribuição pré-estabelecida de tarefas, previamente estabelecidas pela chefia de enfermagem, dentro de uma norma institucional.

Assim como evidenciamos a disciplinarização do espaço da UTI, observamos que algumas anotações no Livro dos Enfermeiros revelaram a busca pela manutenção do controle do espaço e materiais.

“Carrinho de Emergência: Desde sábado - aberto sem reposição. Solicito que todas as vezes que fizerem uso do carrinho reporem; há técnico da farmácia em todos os períodos. Na impossibilidade, fazer uma lista do utilizado e deixar na unidade. Os dois cardioversores estão em funcionamento" (Registro de Observação de 11/04/07).

Há uma expectativa de monitoramento da unidade, onde são indicadas algumas falhas no processo de trabalho e que fogem à normalidade instituída na UTI. Ao mesmo tempo, questiona que, se "há um técnico na farmácia em todos os períodos", por que isso ocorreu? A não reposição do carrinho de emergência poderia causar sérios danos, caso ocorresse a necessidade da sua utilização nesse período em que ficou sem reposição.

As anotações do Livro dos Enfermeiros, que se encontra nesse espaço (posto de enfermagem), trazem anotações referentes ao andamento administrativo, como a falta de materiais e 
equipamentos, a organização do serviço, além do repasse de informações do quadro dos pacientes e sua evolução por plantão e intercorrências, demonstrando a preocupação dos enfermeiros com os usuários e a assistência prestada.

A prática das anotações na UTI representa uma forma de controle ou monitoramento desse espaço pelos profissionais, de forma a envolver não só a organização e funcionamento da unidade, mas também, monitorar as pessoas doentes e os profissionais que ali se concentram.

\section{As relações entre profissionais de saúde e familiares desses usuários}

Em meio à variedade de profissionais que desenvolvem suas atividades na UTI, diferentes relações se estabelecem e interferem nas práticas assistenciais, na perspectiva de operacionalizar a assistência às pessoas que se encontram em condição de gravidade. Entretanto, quando nos referimos ao contato com as pessoas internadas, este se torna dificultado, seja pelo quadro neurológico ou pela indução à inconsciência que grande parte dessas pessoas vivencia no período em que se encontram internadas.

Embora a maior parte das pessoas internadas na UTI se encontre abolida de sua consciência e, portanto, impedida de experimentar relações dialógicas com os profissionais que lhes prestam assistência, foi possível observar a demonstração de preocupação por parte da profissional de enfermagem em relação à evolução de um doente, como na observação que segue.

Quando chegamos na UTI, notamos que o leito 7 havia sido ocupado por um outro paciente. Perguntamos pelo Sr. Luís que ocupava o leito 7. Nesse leito, havia outro paciente. No último dia que estivemos na UTI, o quadro do Sr. Luís era grave. Dolores disse-nos que o Sr. Luís havia saído de alta, mas preocupava-se por achar que ele teria seqüelas (Registro de Observação de 02/05/07).

A preocupação da profissional de enfermagem pode ser relativa à característica do trabalho de enfermagem, uma vez que esta categoria passa a maior parte do tempo com as pessoas ali internadas. Isso possibilita o estreitamento de laços entre esses profissionais e as pessoas doentes, o que é peculiar da profissão pela execução de cuidados em tempo integral, que vai desde o banho no leito, a administração de medicamentos, a realização de mudança de decúbito, dentre outros.

A enfermagem ao buscar atender o doente em todas as suas necessidades se diferencia das práticas exercidas por outros profissionais. Entretanto, embora diferenciadas, as práticas de enfermagem tendem a se conformar de acordo com o modelo clínico, o qual privilegia o atendimento à doença do doente e não ao doente que está com a doença, assim como o olhar médico o faz. Essas práticas se constituem numa forma de violência não intencional ao doente por parte dos profissionais de saúde.

As pessoas hospitalizadas, no caso da UTI, geralmente, dependem totalmente dos profissionais que as assistem, e se vêem incondicionalmente obrigadas a depositar no serviço e nos profissionais de saúde, toda a sua confiança e esperança para a recuperação. Portanto, nesse momento, cria-se um elo entre a equipe assistencial e a pessoa doente e seus familiares, principalmente por ser um espaço caracterizado por dor e sofrimento.

O estabelecimento de vínculo resgata o cuidado em saúde, na perspectiva de uma atenção mais humanizada e comprometida com a pessoa doente, que não se resume apenas na atenção às suas necessidades biológicas, mas também, abrange suas dimensões psicológicas, sociais e culturais, sendo necessário que os profissionais de saúde considerem as pessoas internadas neste espaço para além da doença.

As práticas do cotidiano na UTI nem sempre são apenas mecânicas. O fato de Maria das Graças sentirse emocionada em ver como os familiares estavam contentes com o pequeno sinal de melhora do paciente, mostra que os profissionais, apesar de não demonstrarem, apresentam sentimentos de felicidade quando percebem melhora daqueles por quem prestam cuidados de saúde, e preocupam-se com eles mesmos após a alta da UTI (Diário de Campo de 02/05/07).

No processo da criação ou do estabelecimento do vínculo, o momento da escuta é importante e deve ser considerado pelos profissionais de saúde. Há autores que ressaltam a importância da interação entre profissionais e usuários através do estabelecimento de relações dialógicas entre eles(18), uma vez que as relações humanas constituem importante fator na contraposição causada pelo incômodo que aparato tecnológico e a complexidade da UTI causam.

Relatamos abaixo uma situação de assistência de enfermagem a um banho no leito na UTI.

No início de um banho no leito, nos surpreendemos com a atitude de Amanda:- Ele falou! Ele falou mesmo intubado! Exclamou em tom de voz alta e assustada com a atitude do Sr. Mário. Surpresas, fomos até o leito do Sr. Mário. Percebemos que o Sr. Mário, aparentemente semi-consciente, tentava murmurar, mesmo intubado e sob ventilação mecânica, algo como está frio ou frio ou não. Não conseguíamos entender. Quando olhamos em seu tórax e braços, percebemos que estava todo arrepiado. Amanda disse que a água do banho estava fria e que não tinha água quente na unidade e nem ao menos um "rabo quente" (aparelho para esquentar a água) e que ficava com pena, mas que tinha que fazer o banho. Ela ainda disse: - Ah, assim 
que eu puder, eu mesma vou comprar um rabo quente prá essa UTI... E continuou o procedimento. (Registro de Observação de 02/04/07).

A higiene corporal das pessoas ali internadas constitui um fator de importância na sua recuperação, bem como no seu conforto e bem estar. O confinamento no leito, além de trazer aumento do stress, traz o acúmulo maior de sujidade ou secreções pelos diferentes tratamentos ministrados.

Entretanto, fases de incapacidade de locomoção ou estado de inconsciência tornam muitas pessoas passivas a cuidados que antes eram realizados por si mesmas, como a higienização. Assim, sujeitando-se ao banho no leito, que não reproduz as mesmas sensações que o banho de chuveiro possibilita, ainda se sujeitam à exposição do próprio corpo ${ }^{(19)}$. Percebe-se que, para os pacientes, o banho no leito tem outro significado, ou seja, uma experiência difícil de ser superada, permeada por estresse, ataque a auto-estima, perda da autonomia e constrangimento ${ }^{(19)}$.

Nesse aspecto, para uma boa prática do cuidado em saúde, é importante que o profissional de saúde se coloque no lugar do outro, sendo necessário que sejam vislumbradas as dimensões humanas no atendimento prestado ${ }^{(20)}$.

Ao se colocar no lugar do outro, o profissional de saúde pode se identificar com os sentimentos da pessoa doente e reconhecer que além da dimensão biológica, outras dimensões são afetadas. Identificando-se com a pessoa doente, o profissional pode sentir receio, medo ou angústia, causando em si mesmo o enfrentamento dos seus próprios medos, levando-o a refletir sobre seus próprios modos de agir no cuidado do outro".

Assim, a empatia tende a despertar e a subsidiar reflexões no profissional sobre o cuidado a ser prestado ao doente, o que certamente vai em direção ao atendimento ao princípio da integralidade. O profissional de saúde pode, dessa forma, promover o atendimento às dimensões afetadas da pessoa doente, incorporando atitudes que visem os aspectos físicos, psíquicos e espirituais deste, contribuindo para a minimização do seu sofrimento(20).

\section{CONSI DERAÇÕES FI NAIS}

Num espaço como o da UTI, é grande o desafio para que as práticas assistenciais atendam à integralidade, uma vez que nesse espaço, privilegiam-se determinadas formas de relações como as do saber-poder, constituindo-se como um obstáculo para que as práticas profissionais vislumbrem a perspectiva de mudança nas formas de atenção em saúde. As relações saber-poder, embasadas na hegemonia da ciência médica constituem uma normalidade entre os profissionais de saúde e suas práticas neste espaço, uma vez que estas revelam mecanismos de dominação e de disputas entre esses atores, levando a relações assimétricas que perpassam, inclusive, as relações com os usuários.

Assim, a dinâmica de funcionamento da UTI, geralmente, complexa, tensa, desgastante e traumatizante, corrobora para que as relações entre as pessoas nem sempre sejam pautadas no respeito e na compreensão. Seu contexto relacional causa mudanças comportamentais entre as pessoas, gerando situações de conflito, insensibilidade e indiferença, seja entre os profissionais, seja entre os profissionais e usuários.

O espaço na UTI deve se conformar para buscar a superação de vários paradigmas, romper com conceitos historicamente construídos, as dicotomias existentes entre o pensar e agir em saúde, ampliando os processos dialógicos e a escuta ampliada por parte dos profissionais de saúde para com as pessoas assistidas. Dessa forma, tornam-se possíveis práticas que contemplem as necessidades e minimizem o sofrimento de pessoas que, num determinado momento de suas vidas, necessita de um atendimento complexo e especializado em saúde.

No estudo, foi possível visualizar que na UTI estudada, as práticas profissionais estão embasadas no modelo clínico, evidenciado pela forma como a instituição de saúde disponibiliza o seu espaço e pelas relações sociais que ocorrem nesses espaços. A pessoa doente e em condição de gravidade na unidade de terapia intensiva estudada, tem a assistência focalizada sobre suas funções fisiológicas afetadas, denunciando a existência de lacunas na assistência às demais necessidades ou dimensões afetadas.

Portanto, os resultados do estudo sinalizam para a necessidade de reflexões acerca da assistência na UTI, de forma a contemplar as necessidades das pessoas numa perspectiva mais integral, uma vez que esses espaços não demonstram privilegiar as pessoas que ali se encontram gravemente doentes.

Apesar da Constituição Federal e da Lei Orgânica da Saúde determinarem, respectivamente, os direitos dos cidadãos e como deve estar organizado o SUS em nosso país, podemos perceber que a integralidade, um dos princípios básicos da assistência em saúde, ainda se constitui num paradigma a ser modificado nas instituições e nos comportamentos dos profissionais de saúde. Essa mudança de comportamentos representa a principal ferramenta para a prática da integralidade na UTI, resgatando o compromisso com os usuários dos serviços, no atendimento às suas reais necessidades biopsicosociais, ou seja, de ser cuidado de forma ética.

Assim, reconhecemos que muito ainda há a ser realizado em termos de estudos e reflexões acerca da concepção de atendimento integral na assistência em UTI. Esperamos que este estudo possa contribuir 
para a reflexão tanto por parte dos profissionais quanto para os gestores dos serviços de saúde, para que possam repensar suas práticas na perspectiva de se colocarem na posição dos usuários dos serviços que buscam por um atendimento mais humanizado e integral.

\section{REFERÊNCI AS}

1. Lei $n$ o. 8080 de 19 de setembro de 1990. Dispõe sobre as condições para a promoção, proteção e recuperação da saúde, a organização e o da saúde, a organização e o funcionamento dos serviços correspondentes e da outras providências. Diário Oficial da União (Brasília). 1990 Sep 20.

2. Mattos RA de. Os Sentidos da Integralidade: algumas reflexões acerca de valores que merecem ser defendidos. In: Pinheiro R, Mattos RA de, editors. Os Sentidos da Integralidade na atenção e no cuidado à saúde. Rio de Janeiro: ABRASCO; 2001. p. 39-64.

3. Secretaria Executiva, Ministério da Saúde. O SUS de A a Z: garantindo a saúde nos municípios. Brasília (Brasil): Ministério da Saúde; 2005. 344 p.

4. Mattos RA de. A integralidade na prática (ou sobre a prática da integralidade). Cad. Saúde Pública. 2004;20(5): 1411-6.

5. Mattos RA de. Direito, Necessidades de Saúde e Integralidade. In: Pinheiro R, Mattos RA de, editors. Construção Social da Demanda: direito à saúde, trabalho em equipe, participação e espaços públicos. Rio de Janeiro: ABRASCO; 2005. p. 33-46.

6. Costa AM. Integralidade na atenção e no cuidado a saúde. Saude soc. 2004;13(3): 5-15.

7. Guirardello E de B et. al. A percepção do paciente sobre sua permanência na Unidade de Terapia Intensiva. Rev. esc. enferm. USP. 1999; 33(2): 123-9. 8. Severo GC, Girardon-Perlini NMO. Estar internado em Unidade de Terapia Intensiva: percepção de pacientes. Scientia Médica. 2005; 15(1): 21-29.

9. Kamiyama Y. Assistência centrada na identidade social: aspectos psico-sociais do cuidado de enfermagem ao paciente com hepatite infecciosa [thesis]. São Paulo: Escola de Enfermagem/USP; 1979. $191 \mathrm{p}$.

10. Landim FLP, Lourinho LA, Lira, RCM, Santos, ZMSA. Uma reflexão sobre as abordagens em pesquisa com ênfase na integração qualitativoquantitativa. Revista Brasileira em Promoção da Saúde. 2006; 19(1):53-8.

11. Minayo MC. O Desafio do Conhecimento: pesquisa qualitativa em saúde. 8nd ed. São Paulo: Hucitec; 2004.

12. Victora CG, Knauth DR, Hassen MNA. Pesquisa qualitativa em saúde: uma introdução ao tema. Porto Alegre: Tomo Editorial; 2000.

13. Martins J de J, Nascimento ERP do. A Tecnologia e a Organização do Trabalho da Enfermagem em UTI.
Arquivos Catarinenses de Medicina. 2005; 34(4):2327.

14. Bellato R. A vivência da hospitalização pela pessoa doente [thesis]. Ribeirão Preto: Escola de Enfermagem/USP; 2001. 117 p.

15. Foucault M. Microfísica do poder: O nascimento do hospital. 10nd ed. São Paulo: Graal; 1992.

16. Machado R. Por uma genealogia do poder. In: Foucault M. Microfísica do poder. Rio de Janeiro: Edições Graal; 1992. p VII-XXIII.

17. Dreyfus $\mathrm{HL}$, Rabinow $\mathrm{P}$, Michel Foucault. Uma trajetória filosófica: para além do estruturalismo e da hermenêutica. Rio de Janeiro: Forense Universitária; 1995.

18. Nascimento KC, Erdmann AL. Cuidado Transpessoal de Enfermagem a Seres Humanos em Unidade Crítica. Rev. enferm. UERJ .2006; 14(3):33341.

19. Maciel SSA, Bocchi SCM. Compreendendo a lacuna entre a prática e a evolução técnico-científica do banho no leito. Rev Latino-am Enfermagem. 2006; 14(2): 233-42.

20. Maruyama SAT. A experiência da colostomia por câncer como ruptura biográfica da visão dos portadores, familiares e profissionais de saúde: um estudo etnográfico [thesis]. Ribeirão Preto: Escola de Enfermagem/USP; 2004. 286 p.

Artigo recebido em 25.11.07.

Aprovado para publicação em 25.05.09. 